\title{
No long-term impact of low-energy distal radius fracture on health-related quality of life and global quality of life: a case-control study
}

\author{
Gudrun Rohde*1,2, Glenn Haugeberg1, Anne Marit Mengshoel2, \\ Torbjorn Moum ${ }^{3}$ and Astrid K Wahl2,4
}

\begin{abstract}
Address: ${ }^{1}$ Department of Rheumatology, Sorlandet Hospital, Kristiansand, Servicebox 416, 4604 Kristiansand, Norway, ${ }^{2}$ Institute of Nursing and Health Sciences, Medical Faculty, University of Oslo, Pb.1153 Blindern, 0316 Oslo, Norway, ${ }^{3}$ Department of Behavioural Sciences in Medicine, Medical Faculty, University of Oslo 1111, Blindern, 0317 Oslo, Norway and ${ }^{4}$ Centre for Shared Decision Making and Nursing Research Rikshospitalet, N-0027 Oslo, Norway

Email: Gudrun Rohde* - gudrun.rohde@sshf.no; Glenn Haugeberg - glenn.haugeberg@sshf.no;

Anne Marit Mengshoel - a.m.mengshoel@medisin.uio.no; Torbjorn Moum - torbjorn.moum@medisin.uio.no; Astrid KWahl - a.k.wahl@medisin.uio.no

* Corresponding author

Published: 25 August 2009

BMC Musculoskeletal Disorders 2009, 10:106 doi:10.1186/147I-2474-10-106

This article is available from: http://www.biomedcentral.com//47/-2474//10/106

(C) 2009 Rohde et al; licensee BioMed Central Ltd.

This is an Open Access article distributed under the terms of the Creative Commons Attribution License (http://creativecommons.org/licenses/by/2.0), which permits unrestricted use, distribution, and reproduction in any medium, provided the original work is properly cited.

Received: 29 March 2009

Accepted: 25 August 2009
\end{abstract}

\begin{abstract}
Background: Changes in patient-reported outcomes like health related quality of life (HRQOL) and global quality of life (GQOL) in patients with low-energy distal radius fracture might be related to fracture, or be within the normal range of variation in an elderly population. Hence, the present study aims to examine: Whether patients with low-energy distal radius fracture attain their prefracture levels in HRQOL and GQOL one year after the fracture and compare these levels with age- and sex-matched controls; and whether objective factors predict changes in HRQOL and GQOL during the same one year period.

Methods: We examined 160 patients and 169 age- and sex matched controls, respectively (mean \pm SD) $67 \pm 9$ and $66 \pm 9$ years of age. HRQOL was assessed by the Modified Health Assessment Questionnaire (MHAQ) and the Short-Form 36 (SF-36). The Quality of Life Scale (QOLS) assessed GQOL. Paired sample t-tests and multiple linear regression analyses were applied.

Results: After one year no differences were found in HRQOL (assessed as arm functions, physical health and mental health) compared to pre-fracture level in the patient group. Both patients with distal radius fracture and controls reported a reduced GQOL after one year $(\mathrm{p}<0.00 \mathrm{I})$. Lowenergy distal radius fracture did not predict worsened HRQOL or GQOL one year after inclusion, and few predictors of changes were identified. Worsened arm function was predicted by low BMI $(B=-0.20, p=0.019)$ at baseline, worsened physical health was predicted by low education $(B=$ I.37, $p=0.017)$ at baseline, and living with someone predicted worsened mental health $(B=2.85$, $\mathrm{p}=0.009)$
\end{abstract}

Conclusion: Patients with a distal radius fracture seem to manage well despite the fracture, and distal radius fracture is not an independent predictor of worsened HRQOL and GQOL. 


\section{Background}

The distal radius is a frequent site of osteoporotic fractures in elderly and seems to occur most frequently among relatively healthy elderly people $[1,2]$. Distal radius fractures do also occur about 15 years earlier in life than other osteoporotic fractures like hip fractures $[3,4]$. Furthermore, a low-energy distal radius fracture has been identified as a predictor of future fracture of both hip and spine [4]. Patients with low-energy distal radius fractures report reduced arm functions and pain the first weeks after the fracture, and some patients may never regain pre-fracture arm functions [5-7]. This may impact quality of life (QOL).

QOL cover different physical, psychological and social aspects, and emphasize the patients' perception of these aspects. QOL comprises both health-related quality of life (HRQOL) defined as an individuals' experience of their general state of health, such as physical, social, and mental well-being [8] and global quality of life (GQOL) reflecting an individuals' satisfaction with life, and has a meaning beyond an individuals' health [9].

To identify changes in subjective outcomes such as HRQOL and GQOL after a fracture might give patients and their caregivers a better understanding of expected recovery. Previous studies of HRQOL after distal radius fractures have shown that most recovery in arm functions occurs during the first 6 months after the fracture, and at one year follow-up most patients report no or minimal pain and disability $[6,10-12]$. Furthermore, patients with a distal radius fracture seem to reach population-based levels of HRQOL some time after the fracture, although numerous patients report remaining symptoms from the fracture $[5,7]$. Education, co-morbidities and injury compensation at baseline seem to be covariates of how patients report their pain and disability one year after a distal radius fracture, indicating that also factors independent of the injury play a role in self-reported arm functions after the fracture [13]. In other studies, low bone mineral density (BMD) and low body mass index (BMI) are identified as determinants of reduced HRQOL two years after a distal radius fracture [7].

Previous research on patients with low-energy fracture seems to lack a broader perspective in one and the same study, including both objective factors, such as BMD, BMI and other demographic and clinical measures, as well as patient-reported outcome like HRQOL and GQOL. Presently, all these variables are assessed. Furthermore, we ask whether the changes in HRQOL and GQOL in patients with low-energy distal radius fracture are related to the fracture or within the normal range of variation in an elderly population [14]. Hence, the present study aims to examine:
1) Whether patients with low-energy distal radius fracture attain their pre-fracture levels in HRQOL and GQOL one year after the fracture, and compare these levels with ageand sex-matched controls;

2) Whether objective factors predict changes in HRQOL and GQOL during the same one year period.

\section{Methods \\ Study design, patients and controls}

To study one-year changes in HRQOL and GQOL in patients with low-energy distal radius fracture we applied a case-control, prospective longitudinal study design. The study was recommended by the Regional Committee for Medical Research Ethics and approved by the National Data Inspectorate.

Patients with low-energy distal radius fracture aged 50 years and older were consecutively recruited from an osteoporosis centre at a regional hospital in southern Norway in 2004 and 2005. A low-energy fracture was defined as a minimal trauma falling from standing height or less [15], and a distal radius fracture was defined as located within $3 \mathrm{~cm}$ of the radio-carpal joint [16]. The distal radius fractures were closed injuries, and the fractures were treated conservatively by stabilising the fracture by a plaster cast or by external fixation. Patients were assessed and data collected in median 10 days (interquartile range 13) after fracture and reassessed one year after fracture. With regard to demographical and clinical variables, HRQOL and GQOL the patients were asked to report their status prior to fracture. The patients also were asked to report their exercise habits, falls and the use of health care recourses during the year before fracture. The controls were asked about their status and habits prior to inclusion. The same data collection performed at baseline was repeated after one year.

The included patients comprised $56 \%$ of all 324 patients with low-energy distal radius fracture treated at the hospital, and $73 \%$ of 249 patients examined at the osteoporosis centre. Before inclusion in this study, we confirmed that the fracture was not a result of high-energy trauma and was caused only by minimal trauma according to the definition of low-energy fracture [17]. Patients who were excluded comprised a total of 51 patients with confusion or dementia, serious infection, patients not capable of giving informed consent, patients not capable of speaking Norwegian or tourists and 92 patients who did not want to participate in the study.

At baseline 181 patients with distal radius fracture were included along with 181 age- and sex-matched controls. The age- and sex-matched controls were randomly allocated from the national registry for the catchment area 
and invited by mail to participate in the study. The controls were identified consecutively along with patient recruitement. If a potential control refused to participate or did not respond to the invitation, a new control was invited. Overall, 131 potential controls refused to participate or did not respond to the invitation. We aimed an age match of \pm 1 year in the patients with distal radius fracture; however, this was a challenge for some of the patients aged 80 years and older. In these patients we accepted a match of \pm 5 years, except for one woman aged 96 years who was matched with an 86 years old control.

\section{Demographical and clinical variables}

Demographical and clinical data (listed in table 1) were collected, and included also exercise, smoking habits, medication, previous fracture, number of falls the year before the fracture, and co-morbidity. Furthermore, patients and controls reported their use of health care resources; like visiting general practitioners, medical specialists, physiotherapists, and hospitalization the year prior to the fracture or prior to inclusion in the control group. Regular exercise was defined as walking or doing more intensive exercise more than 30 minutes three times a week. Previous fracture was defined as a low-energy trauma fracture after the age of 50. Co-morbidity included heart diseases, pulmonary diseases, neurological disorders, urogenital disorders, gastrointestinal disorders, endocrine disorders, inflammatory joint disorders and connective tissue disorders, cancer, mental disorders. For co-morbidity, we also computed a sum score of the number of diseases in each patient and control, which was used in the multivariate analyses.

\section{Bone density measurements}

Standardized BMD measurements at lumbar spine L2-4 and both hips were performed by four trained nurses

Table I: Baseline demographical and clinical characteristics in patients with low-energy distal radius fracture and controls who visited the osteoporosis centre at both inclusion and at one year follow up.

\begin{tabular}{|c|c|c|c|}
\hline & $\begin{array}{l}\text { Distal radius fracture } \\
n=160\end{array}$ & $\begin{array}{l}\text { Controls } \\
n=169\end{array}$ & p* \\
\hline \multicolumn{4}{|l|}{ Demographics } \\
\hline Age (years; mean (SD)) & $67(9)$ & $66(9)$ & 0.457 \\
\hline Females & $144(90)$ & $15 \mid(89)$ & 0.846 \\
\hline BMI $\left(\mathrm{kg} / \mathrm{m}^{2}\right)$ & $25.7(4.3)$ & $26.7(4.3)$ & 0.027 \\
\hline Menarche (years; mean (SD)) & $13.9(1.5)$ & $13.6(1.4)$ & 0.066 \\
\hline Menopause (years; mean (SD)) & $48.9(4.5)$ & $49.6(4.1)$ & 0.086 \\
\hline Education & & & 0.011 \\
\hline$<10$ years & $56(38)$ & $70(42)$ & \\
\hline $11-13$ years & $61(42)$ & $45(27)$ & \\
\hline$>13$ years & $30(20)$ & $53(31)$ & \\
\hline Co-habiting & $84(53)$ & $112(67)$ & 0.011 \\
\hline Regular exercise** & $119(74)$ & $126(74)$ & 0.970 \\
\hline Current smoker & $23(14)$ & $2 I(12)$ & 0.604 \\
\hline \multicolumn{4}{|l|}{ Clinical characteristics } \\
\hline Current calcium and/or vitamin $\mathrm{D}$ treatment & $39(24)$ & $4 \mid(24)$ & 0.981 \\
\hline Current ART & $28(18)$ & $22(13)$ & 0.258 \\
\hline Previous fractures & $83(52)$ & $77(47)$ & 0.319 \\
\hline$\geq I$ fall in the previous year & $68(47)$ & $48(36)$ & 0.054 \\
\hline Osteoporosis & $52(32)$ & $30(18)$ & $<0.001$ \\
\hline Osteopenia & $83(52)$ & $74(44)$ & \\
\hline Normal BMD & $25(16)$ & $64(38)$ & \\
\hline Heart diseases & $48(30)$ & $58(34)$ & 0.402 \\
\hline Pulmonary diseases & $19(12)$ & $12(7)$ & 0.138 \\
\hline Neurological diseases & $12(8)$ & $14(8)$ & 0.792 \\
\hline Endocrine disorders & $14(9)$ & $20(12)$ & 0.358 \\
\hline Gastrointestinal disorders & $8(5)$ & $21(12)$ & 0.018 \\
\hline Urogenital disorders & $5(3)$ & $\mathrm{I}(\mathrm{I})$ & 0.086 \\
\hline Inflammatory joint disorders and connective tissue disorders & $36(23)$ & $45(26)$ & 0.385 \\
\hline Cancer & $16(10)$ & $19(11)$ & 0.715 \\
\hline Mental disorders & $7(4)$ & II (7) & 0.395 \\
\hline Co-morbidities (range 0-6) & $1.0(1.0)$ & $1.2(1.1)$ & 0.191 \\
\hline
\end{tabular}

Mean (SD) for continuous variables and numbers (\%) for categorical variables.

*Bold $\mathrm{p}$-values indicate significant differences between the groups

** Exercise more than 30 minutes three times a week.

BMI, body mass index; ART, antiresorptive treatment, a specific osteoporosis treatment comprising biphosphonates, or selective oestrogenreceptor modulators. 
using the same dual energy X-ray absorptiometry (DXA) equipment (General Electric, Lunar Prodigy) at baseline and at one year follow-up. The machine was stable over the entire measurement period. Long term spine phantom in-vitro coefficient of variation (CV) for the whole period was $0.62 \%$. The in-vivo CV for the measurement procedure was $1.19 \%$ at lumbar spine L2-4, 0.95\% at right total hip and $0.89 \%$ at left total hip. The BMD measurements were expressed as T-scores (SD) calculated on the basis of the reference value in the DXA machine provided by the manufacturer. Osteoporosis was defined as T-score $\leq-2.5$ SD, osteopeniae as T-score $>-2.5$ and $<-1.0$ and normal $\mathrm{BMD}$ as T-score $>-1.0$, according to the WHO definition for osteoporosis [17].

\section{Modified Health Assessment Questionnaire (MHAQ)}

Modified Health Assessment Questionnaire (MHAQ) measures a patients ability to perform activities of daily living $[18,19]$. Although primarily developed as a measure for use in rheumatoid arthritis, MHAQ has been used across a variety of diseases [20]. The MHAQ consists of 8 items covering daily activities including skills that demand a good arm function e.g. dressing, lift a full cup or glass to the mouth, wash and dry the entire body $[18,19]$. The total mean scores range from $1-4$, with 1 representing "without any difficulty". For incomplete questionnaires, the missing values were replaced with the mean value of the answered questions of the respondent when at least 6 out of 8 items had valid response, which is based on the scale instructions given by the developers of the questionnair [20,21]. At baseline all the the patients and controls had valid responses. At one year follow-up $1,5 \%$ of the patients and $1 \%$ of the controls had one or two missing responses. In the multivariate analyses, which were performed to identify if a low-energy distal radius fracture was a predictor of worsened arm functions, we rescaled MHAQ from 0 to 100, with 100 representing "without any difficulty" in accordance with prior studies $[21,22]$.

\section{Short Form - 36 (SF-36)}

The Short- Form 36 (SF-36) was used to assess HRQOL (physical and mental health) [23,24]. The SF-36 includes eight domains (general health, bodily pain, physical functioning, physical role limitations, mental health, vitality, social functioning, and emotional role limitations), which can be combined into a physical health summary scale and a mental health summary scale. The physical component summary (PCS) and mental component summary (MCS) scales were used in this study. The SF-36 scales were scored according to published scoring procedures, and each was expressed as a value from 0 to 100 , with 100 representing "excellent health". For incomplete questionnaires substitution of missing values is based on the scale instructions given by the developers of the ques- tionnaire $[23,24]$. At baseline $5.6 \%$ of the patients and $13.5 \%$ of the controls had one or more missing responses. At one year follow-up $18.8 \%$ of the patients and $14 \%$ of the controls had one or more missing responses. The questionnaire has been thoroughly tested for psychometric properties in other studies, within several countries, including Norway [23-26].

\section{Quality of Life Scale (QOLS)}

The Quality of Life Scale (QOLS), a 16-item, domain-specific instrument adapted by Burckhardt et al. for people with chronic conditions, was used to assess GQOL $[9,27,28]$. In this questionnaire GQOL is understood as a broad range of human experiences related to one's overall well-being and satisfaction. The QOLS is a self-administered questionnaire $[27,29]$. The items are rated at a 7 point satisfaction scale. For incomplete questionnaires, the missing values were replaced with the mean value of the answered questions of the respondent when at least $80 \%$ of the items had a valid response. The substitution of missing values is based on the scale instructions given by the developers of the questionnaire [9,27]. At baseline $26 \%$ of the patients and $23 \%$ of the controls had one or more missing responses. At one year follow-up 35\% of the patients and $33 \%$ of the controls had one or more missing responses. The items with most missing responses were QOLS item number four (having and rearing children) and item five (close relationship with spouse or other significant other).

The questionnaire is scored by adding up the items to obtain a total score from a minimum of 16 to a maximum of 112. Higher scores indicate better GQOL. Burckhardt et al. [28] suggested that the QOLS comprising three subdimensions: relationship and marital well-being (items 3, 4, 5, 6, and 14); health and functioning (items 1, 2, 11, 15 , and 16); and personal, social, and community commitment (items 7, 8, 9, 10, 12, and 13) [28,30]. The three dimensions are scored by summing the scores for each item in the dimension. The questionnaire has been thoroughly tested for psychometric properties in other studies, within several countries [28,30-32].

\section{Statistical analysis}

Statistical analyses were carried out using the Statistical Package for Social Sciences (SPSS) for Windows (version 16.0). Chi-square tests and t-tests were used to compare differences between subgroups. Wilcoxon rank tests were used to compare continuous health care resources data between inclusion and one year follow-up, and paired samples t-tests were used to compare HRQOL and GQOL at inclusion and one year follow-up within the patients with distal radius fracture and within the controls. Furthermore, standard difference scores (s-scores) were calculated by subtracting the mean MHAQ, SF-36 or QOLS 
scores at baseline from the mean score of one year followup, and then dividing by the standard deviation (SD) at baseline [33]. To estimate the proportion of patients and controls with clinically significant changes in HRQOL and GQOL, we also identified participants with modest changes (between -5 and -10\%), moderate changes (between -10 and -20\%) and substantial changes (more than $-20 \%$ ) between baseline and one year follow-up $[33,34]$

Multiple linear regression analyses (procedure GLM in the SPSS) were used to identify significant predictors of worsened HRQOL (delta total mean MHAQ, SF-36; delta PCS and delta MCS) or GQOL (delta QOLS) in the study-population (both patients and controls). The regression analyses were adjusted for baseline total mean MHAQ (rescaled), PCS, MCS or QOLS respectively, at inclusion. The independent variables in the multiple regression analyses were selected based on results from earlier studies which show that age, sex, education level, marital status, $\mathrm{BMD}$, falls, BMI, co-morbidity and osteoporotic fractures appear to be associated with HRQOL and/or GQOL, and these variables were all included in the regression model [14]. To test if the effects of predictors of change in our dependent variables were significantly different for patients and controls, interaction terms involving the patient/control dichotomy and each of the predictors were entered one pair at a time, while retaining main effects in the model. The level of significance was set at 0.05 .

\section{Results}

\section{Respondents}

The patients in the study were significantly $(\mathrm{p}<0.001)$ younger ( $67 \pm 9$ years) than the excluded patients $(76 \pm 12$ years) and those who did not want to participate $(72 \pm 11$ years). Among the 181 patients with distal radius fracture and 181 controls included at baseline, 160 patients and 169 controls attended the osteoporosis-centre at one year follow-up. There were minor differences between participants at one year follow-up and participants who were lost to follow-up. Among patients with distal radius fracture a statistically significant difference was only reported for gastrointestinal disorders $(\mathrm{p}=0.015)$. Among controls, those who were lost to follow-up were significantly older $(\mathrm{p}=0.046)$, and reported significantly lower SF-36 score in vitality $(\mathrm{p}=0.014)$.

\section{Demographical and clinical characteristics and use of health care resources}

Socio-demographical and clinical characteristics at baseline of those participants who completed both baseline and one year follow-up assessments are shown in table 1.

Patients with distal radius fracture more often were living alone $(p=0.011)$, had fewer years of education $(p=$
0.011), had lower BMI ( $p=0.027)$, and were more frequently classified with osteoporosis $(\mathrm{p}<0.001)$ compared to the controls. The distal radius fracture occurred indoors in $31(19 \%)$ patients and outdoors in 129 patients $(81 \%)$. Mean age in patients whose fracture occurred indoors was $70 \pm 11$ years old and outdoors $66 \pm 9$ years old $(\mathrm{p}=$ $0.074)$.

At one year follow-up, the patients with distal radius fracture compared with controls were also more frequent user of calcium and/or vitamin D treatment (103 vs. 88, p = 0.024 ) and antiresorbtive treatment (ART) (52 vs. 27, p < 0.001 ). Four patients with distal radius fracture and no controls got a new fracture between inclusion and oneyear follow-up $(\mathrm{p}=0.069)$.

During the one year follow-up, patients with distal radius fracture on average visited their general practitioner more frequently than the year before fracture ( 3.9 vs. $3.4, \mathrm{p}=$ 0.006 ). There were no significant differences with regard to the number of visits to other health care providers, like medical specialists $(\mathrm{p}=0.083)$, physiotherapist $(\mathrm{p}=$ 0.139 ) or number of days hospitalized the last year ( $\mathrm{p}=$ 0.581 ), the year following the fracture compared to number of visits the year before fracture. There were no significant changes in the controls.

\section{Changes in HRQOL and GQOL}

No significant changes in arm function as assessed by MHAQ were identified in patients with distal radius fracture at one year follow-up compared to the baseline (prior to fracture) assessment ( $\mathrm{p}=0.202)$ (table 2). Only ten patients $(6 \%)$ with a distal radius fracture did not attain their pre-fracture arm functions one year after fracture.

Furthermore, no significant changes were identified in HRQOL as assessed by the SF-36; physical health ( $\mathrm{p}=$ $0.209)$ and mental health $(\mathrm{p}=0.840)$ from pre-fracture to one year after the fracture in the patients with a distal radius fracture. The same pattern was seen in controls (table 2).

With regard to GQOL, the patients with distal radius fracture reported significantly lower total GQOL score ( $\mathrm{p}<$ 0.001 , s-score $=-0.4)$ and for the sub-dimensions; relationship and marital well-being $(\mathrm{p}=0.015$, s-score $=-0.2)$, health and functioning $(\mathrm{p}=0.001$, s-score $=-0.2)$ and personal, social and community commitment ( $\mathrm{p}<0.001$, sscore $=-0.3$ ) at one year follow-up compared to the baseline assessment (table 3). In the controls we also found significant changes in GQOL scores within both the overall score and the three sub-dimensions $(\mathrm{p}<0.001)$ one year after inclusion, with s-score $=-0.6$ in QOLS, s-score $=$ -0.3 for relationship and marital well being, s-score $=-0.4$, s-score $=-0.4$ for health and functioning and s-score $=-0.6$ 
Table 2: Health-related quality of life in patients with low-energy distal radius fracture and controls at baseline and after one year.

\begin{tabular}{|c|c|c|c|c|c|c|c|c|c|c|}
\hline & \multicolumn{5}{|c|}{ Patients with distal radius fracture $(n=160)$} & \multicolumn{5}{|c|}{ Controls $(n=169)$} \\
\hline & Baseline & One year & $\mathbf{p}$ & Effect size & $\begin{array}{l}\text { Mean change } \\
\text { (SD) }\end{array}$ & Baseline & One year & $\mathbf{p}$ & Effect size & $\begin{array}{l}\text { Mean change } \\
\text { (SD) }\end{array}$ \\
\hline MHAQ* & $1.04(0.16)$ & $1.05(0.21)$ & 0.202 & 0.06 & $0.01(0.1)$ & $1.06(0.22)$ & $1.06(0.20)$ & 0.802 & 0.01 & $0.0(0.2)$ \\
\hline \multicolumn{11}{|l|}{ SF-36 $* *$} \\
\hline PCS & $51.2(9.4)$ & $50.4(9.8)$ & 0.209 & -0.1 & $-0.8(7.6)$ & $51.2(8.4)$ & $51.3(8.6)$ & 0.846 & 0.1 & $0.1(5.9)$ \\
\hline MCS & $50.2(9.9)$ & $50.3(10.5)$ & 0.840 & 0.01 & $0.2(9.2)$ & $51.7(8.4)$ & $51.7(8.6)$ & 0.908 & 0.1 & $0.1(7.2)$ \\
\hline
\end{tabular}

Data are given as means with standard deviation, and paired sample t-tests were applied to detect significant differences between baseline and follow-up.

* the MHAQ scores range from I to 4, where I means high perception of their ability to perform activities of daily living.

** The score for SF-36 ranges from 0 to 100, where 100 means high HRQOL.

$\mathrm{PCS}=$ physical component summary, $\mathrm{MCS}=$ mental component summary, MHAQ = The Modified Health Assessment Questionnaire.

in personal, social and community commitment (table 3).

Modest (-5 to -10$)$ or moderate $(-10$ to -20$)$ worsening arm functions between baseline and one year follow up were reported by $2.5 \%$ of the patients and $3 \%$ of the controls and substantial change ( -20 or more) in 2 patients and one control. Modest or moderate worsening of physical health was reported by $20 \%$ of the patients and $10 \%$ of the controls, and substantial changes in one patient. Modest or moderate worsening of mental health was reported by $19 \%$ of the patients and $14 \%$ of the controls and substantial changes in four patients and in one control. Furthermore, modest or moderate worsening of
GQOL was reported by $35 \%$ of the patients and $42 \%$ of the controls.

No significant differences between the patients with distal radius fracture and controls were identified in HRQOL and GQOL at one year follow-up.

\section{Prediction of changes in HRQOL and GQOL}

A low-energy distal radius fracture did not predict worsened HRQOL or GQOL one year after inclusion, and few predictors of changes were identified. Worsened arm function was predicted by low BMI $(\mathrm{B}=-0.20, \mathrm{p}=0.019)$ at baseline, worsened physical health was predicted by low education $(\mathrm{B}=1.37, \mathrm{p}=0.017)$ at baseline, and living

Table 3: Global quality of life in the patients with low-energy distal radius fracture and controls at baseline and after one year.

\begin{tabular}{|c|c|c|c|c|c|c|c|c|c|c|}
\hline & \multicolumn{5}{|c|}{ Patients with distal radius fracture $(n=160)$} & \multicolumn{5}{|c|}{ Controls $(n=169)$} \\
\hline & Baseline & $\begin{array}{l}\text { After one } \\
\text { year }\end{array}$ & $\mathbf{P} * * * *$ & Effect size & $\begin{array}{l}\text { Mean } \\
\text { change } \\
\text { (SD) }\end{array}$ & Baseline & $\begin{array}{l}\text { After one } \\
\text { year }\end{array}$ & $\mathbf{P} * * * *$ & Effect size & $\begin{array}{l}\text { Mean } \\
\text { change } \\
\text { (SD) }\end{array}$ \\
\hline $\begin{array}{l}\text { Total QOLS- } \\
\text { score * }\end{array}$ & $94.4(10.5)$ & $90.8(12.6)$ & $<0.001$ & -0.4 & $\begin{array}{l}-4.0 \\
(8.9)\end{array}$ & $97.3(8.4)$ & $92.7(10.2)$ & $<0.001$ & -0.4 & $\begin{array}{l}-4.9 \\
(7.8)\end{array}$ \\
\hline $\begin{array}{l}\text { Relationship } \\
\text { and Marital } \\
\text { Well-being** }\end{array}$ & $31.5(3.0)$ & $30.9(3.2)$ & 0.015 & -0.2 & $\begin{array}{l}-0.7 \\
(3.0)\end{array}$ & $32.1(2.9)$ & $31.1(3.0)$ & 0.015 & -0.2 & $\begin{array}{l}-1.0 \\
(2.4)\end{array}$ \\
\hline $\begin{array}{l}\text { Health and } \\
\text { Functioning** }\end{array}$ & $29.1(3.9)$ & $28.2(4.5)$ & 0.001 & -0.2 & $\begin{array}{l}-0.9 \\
(3.2)\end{array}$ & $30.0(3.4)$ & $28.7(4.0)$ & 0.001 & -0.2 & $\begin{array}{l}-1.3 \\
(3.1)\end{array}$ \\
\hline $\begin{array}{l}\text { Personal, } \\
\text { Social and } \\
\text { Community } \\
\text { Commitment } \\
\text { **** }\end{array}$ & $34.0(5.0)$ & $32.3(5.8)$ & $<0.001$ & -0.3 & $\begin{array}{l}-1.8 \\
(4.7)\end{array}$ & $35.2(3.8)$ & $33.0(5.0)$ & $<0.001$ & -0.3 & $\begin{array}{l}-2.1 \\
(4.6)\end{array}$ \\
\hline
\end{tabular}

Data are given as means with standard deviation, and paired sample t-tests were applied to detect significant differences between baseline and follow-up.

* Range from 16 to 112 , where 112 means high GQOL.

**Range 5-35, where 35 means high GQOL.

***Range 6-42, where 42 means high GQOL.

**** $\mathrm{P}$-values marked with bold indicate statistically significant $\mathrm{P}$-values.

QOLS = quality of life scale. 
with someone predicted worsened mental health $(\mathrm{B}=$ 2.85, $\mathrm{p}=0.009)($ table 4).

Interaction terms between pairs of each independent variable and the patients/controls dichotomy (tested one pair at a time, with main effects retained) revealed no significantly different effects between the patients with wrist fracture and the controls in the regression analyses.

\section{Discussion}

A low-energy distal radius fracture was not identified as a significant predictor of worsened HRQOL or GQOL one year after fracture, and the changes in HRQOL and GQOL in patients with low-energy distal radius fracture seem to be within the normal range of variation in an elderly population. Only a small proportion of the patients with a distal radius fracture did not attain their prefracture arm functions one year after fracture, even when using a modest change or slightly decreased function to identify this group [35].

The proportion of patients with distal radius fracture who did not attain their pre-fracture level of physical health (as assessed by the SF-36) was larger than the proportion of

Table 4: Predictors of change in health-related quality of life (delta MHAQ, delta PCS, and delta MCS) and global quality of life (delta QOLS) in both patients with low-energy distal radius fracture $(n=160)$ and controls $(n=169)$.

\begin{tabular}{|c|c|c|c|c|c|c|c|c|}
\hline & $\begin{array}{l}\text { MHAQ Adj B } \\
(95 \% \mathrm{Cl})\end{array}$ & $\mathbf{p}$ & $\begin{array}{l}\text { PCS Adj B } \\
(95 \% \mathrm{CI})\end{array}$ & $\mathbf{p}$ & $\begin{array}{l}\text { MCS Adj B } \\
(95 \% \mathrm{Cl})\end{array}$ & $\mathbf{p}$ & $\begin{array}{l}\text { QOLS Adj B } \\
(95 \% \mathrm{Cl})\end{array}$ & $\mathbf{P}$ \\
\hline \multicolumn{9}{|l|}{ Demographic } \\
\hline \multirow[t]{2}{*}{ Age* } & -0.06 & 0.878 & -0.90 & 0.101 & -0.09 & 0.885 & -0.48 & 0.520 \\
\hline & $(-0.90,0.77)$ & & $(-1.97,0.18)$ & & $(-0.14,0.12)$ & & $(-1.74,0.88)$ & \\
\hline \multirow[t]{2}{*}{ Male } & -0.24 & 0.840 & 0.03 & 0.984 & -0.77 & 0.662 & -2.16 & 0.222 \\
\hline & $(-2.56,2.08)$ & & $(-2.87,2.93)$ & & $(-4.24,2.70)$ & & $(-5.62,1.32)$ & \\
\hline Female & Ref & & Ref & & Ref & & Ref & \\
\hline \multirow[t]{2}{*}{ Education } & 0.83 & 0.060 & 1.37 & 0.017 & -0.27 & 0.690 & 0.57 & 0.390 \\
\hline & $(-0.04,1.69)$ & & $(0.25,2.48)$ & & $(-1.60,1.06)$ & & $(-0.74,1.88)$ & \\
\hline \multirow[t]{2}{*}{ Living alone } & -0.11 & 0.877 & -0.59 & 0.517 & 2.85 & 0.009 & 0.22 & 0.837 \\
\hline & $(-1.51,1.29)$ & & $(-2.37,1.20)$ & & $(0.71,4.99)$ & & $(-1.92,2.37)$ & \\
\hline Living together & Ref & & Ref & & Ref & & Ref & \\
\hline \multicolumn{9}{|l|}{ Clinical } \\
\hline \multirow[t]{2}{*}{ Radius patients } & -0.23 & 0.744 & -0.51 & 0.574 & -1.24 & 0.258 & 0.53 & 0.619 \\
\hline & $(-1.62,1.16)$ & & $(-0.56,0.57)$ & & $(-3.39,0.91)$ & & $(-1.58,2.65)$ & \\
\hline Controls & Ref & & Ref & & Ref & & Ref & \\
\hline \multirow[t]{2}{*}{ Osteopenia** } & -1.22 & 0.143 & -1.08 & 0.301 & -0.76 & 0.547 & -2.41 & 0.051 \\
\hline & $(-2.85,0.4 I)$ & & $(-3.14,0.97)$ & & $(-3.21,1.7 I)$ & & $(-4.82,0.01)$ & \\
\hline \multirow[t]{2}{*}{ Osteoporosis** } & -1.59 & 0.118 & -0.69 & 0.597 & 0.98 & 0.531 & -2.35 & 0.131 \\
\hline & $(-3.58,0.4 I)$ & & $(-3.26,1.88)$ & & $(-2.10,4.05)$ & & $(-5.39,0.70)$ & \\
\hline Normal BMD & Ref & & Ref & & Ref & & Ref & \\
\hline \multirow[t]{2}{*}{ BMI } & -0.20 & 0.019 & -0.15 & 0.178 & -0.06 & 0.630 & -0.25 & 0.054 \\
\hline & $(-0.37,-0.03)$ & & $(-0.36,0.07)$ & & $(-0.19,0.32)$ & & $(-0.5 \mathrm{I},-0.0 \mathrm{I})$ & \\
\hline \multirow[t]{2}{*}{ Co-morbidity } & -0.01 & 0.965 & -0.77 & 0.112 & -0.92 & 0.075 & -0.92 & 0.077 \\
\hline & $(-0.67,0.64)$ & & $(-1.71,0.18)$ & & $(-1.24,1.97)$ & & $(-1.94,0.10)$ & \\
\hline $\begin{array}{l}\geq I \text { fall in the last } \\
\text { year }\end{array}$ & $-1.04(-2.39,0.32)$ & 0.132 & $-1.13(-2.86,0.60)$ & 0.201 & $0.67(-1.42,2.76)$ & 0.527 & $-0.06(-2.10,1.98)$ & 0.953 \\
\hline No fall & Ref & & Ref & & Ref & & Ref & \\
\hline \multicolumn{9}{|l|}{ HRQOL/GQOL } \\
\hline \multirow[t]{2}{*}{ MHAQ incl } & -0.31 & $<0.001$ & & & & & & \\
\hline & $(-0.41,0.14)$ & & & & & & & \\
\hline PCS incl & & & $-0.39(-0.50,-0.28)$ & $<0.001$ & & & & \\
\hline MCS incl & & & & & $-0.36(-0.47,-0.25)$ & $<0.001$ & & \\
\hline QOLS incl & & & & & & & $-0.25(-0.36,-0.13)$ & $<0.001$ \\
\hline $\mathbf{R}_{\mathbf{2}}$ adj & $15.5 \%$ & & $17.7 \%$ & & $16.9 \%$ & & $11.0 \%$ & \\
\hline
\end{tabular}

Regression analyses of demographics, clinical characteristics, and rescaled MHAQ at inclusion of changes in MHAQ/SF-36 at inclusion on change in SF-36/QOLS at inclusion of changes in QOLS. Adjusted unstandardized regression coefficients, $95 \% \mathrm{Cl}$, p values.

$P$-values marked with bold indicate statistically significance.

* Age in decades.

** Osteopenia/osteoporosis at total hip and/or spine L2-L4.

$\mathrm{BMD}=$ bone mineral density, $\mathrm{BMI}=$ body mass index, $\mathrm{MHAQ}=$ Mean total MHAQ (rescaled MHAQ, range 0-100, where 100 means favourable perception of ability to perform activities of daily living), $P C S=$ physical component summary, MCS = mental component summary (range $0-100$, where 100 means perfect health), QOLS = quality of life scale (range 16- II2), where II2 means high GQOL 
patients who did not attain their pre-fracture arm functions (as assessed by the MHAQ). The same pattern of changes was reported by the controls. This might reflect the fact that SF-36, which was used to measure physical health, is comprised of different items or skills than those included in MHAQ, e.g. walking long distances and doing outdoor activities $[18,23,24]$. Such skills deteriorate with aging [36], and the changes in physical health might therefore reflect normal changes or be within the normal range of variation appearing in this age-group.

Despite high levels of GQOL, significantly worsened GQOL was found in both fracture and control group. However, it should be added that separate analyses using comparative data from a nationwide sample indicate that the mean GQOL scores reported at inclusion as well as at one year follow-up by the patients and the controls in the present study were significantly higher than the scores observed in the general Norwegian population [37]. The same pattern of decrease in GQOL over a one year period has been observed within other patient groups $[38,39]$. Furthermore, it might be that those patients and controls who agreed to participate did so at a point in time when their GQOL was better than their own typical (long-term) level, thus creating a "regression to mean" effect when one year later that had returned to their usual level of GQOL [14]. The decreased GQOL scores in both patients with distal radius fracture and controls might be explained by the influence of non-medical factors such as characteristics of the individual and the environment like coping and retirement [40-45], - factors which have not been focused in this study.

Known correlates/covariates of HRQOL and GQOL like demographical and clinical variables could only to a limited extent predict changes in HRQOL and GQOL. Different methods of fracture treatment might have explained some of the changes in HRQOL. However, the methods of treatment used in each case have unfortunately not been included in the study, and Handoll et al [16] showed insufficient evidence to confirm differences in functional outcome between plaster cast and external fixation treatment [16]. Moreover, several studies have shown that diseases or injuries (e.g. a wrist fracture), and HRQOL and GQOL have bidirectional relationships, though all are influenced by characteristics of the individual and the environment $[40,43-46]$. Furthermore, the studies have shown that characteristics of the individuals and the environment influence HRQOL and GQOL differently, and non-medical factors seem to influence GQOL more than HRQOL [40,43-45]. In line with earlier studies, low education seems to be a predictor of changes in self-reported health outcomes $[13,47]$. However, in general it seems difficult to give a plausible substantive explanation of the worsening in HRQOL and GQOL observed in our elderly study-population.

The population-based and unselected group of patients with distal radius fracture along with matched controls may be seen as strengths of the present study. However, this study has some limitations, which should be considered when interpreting the findings. When included in the study briefly after the fracture had occurred, the patients were asked to evaluate their "pre-fracture" HRQOL and GQOL. Changes in health, such as having experienced a fracture, might cause a shift in how the patients perceived their prefracture HRQOL and GQOL (selective reporting bias and response shift) [48]. On the other hand, patients who have experienced a recent change in health have been found to be more likely to give accurate responses $[33,49,50]$. The patients were asked to think of the period before the fracture, and in most of the patients, HRQOL and GQOL were assessed within the first two weeks after the fracture. It seems unlikely that the patients at this point were unable to accurately recall their HRQOL and GQOL immediately before and at the time of the fracture.

We probably reached the healthiest patients with distal radius fracture in our region in our study. The patients unwilling to participate and the excluded patients were significantly older and probably less healthy than the patients included in the study [51]. Our finding might therefore be applied to other relatively healthy patients with distal radius fracture aged 50 years and older.

\section{Conclusion}

Patients with a low-energy distal radius fracture seem to manage well one year after the fracture, and the distal radius fracture is not an independent predictor of worsened HRQOL or GQOL. This might be attributed to the fracture being experienced as a minor trauma and to the successful treatment. The proportion of patients with distal radius fracture who did not attain their pre-fracture HRQOL and GQOL seems to be comparable with the normal range of variation in this age-group. A low-energy distal radius fracture might not be considered a substantial trauma with consequences in the long run, and hence not calling for additional health care efforts.

\section{Abbreviations}

ART: antiresorptive treatment; BMD: bone mineral density; BMI: body mass index; DXA: dual-energy X-ray absorptiometry; GLM: General Linear Model; GQOL: global quality of life; HRQOL: health related quality of life; MCS: mental component summary; MHAQ: Modified Health Assessment Questionnaire; PCS: physical component summary; SF-36: Short Form-36; s-score: standard difference score; QOLS: The Quality of Life Scale; WHO: World Health Organization. 


\section{Competing interests}

The authors declare that they have no competing interests.

\section{Authors' contributions}

GR initiated this paper as a part of a larger study of fracture patients, collected and analyzed the data and wrote the manuscript. $\mathrm{GH}$ was the principal investigator for the study and supervised GR. AM supervised GR during the analyzes and drafting of the paper. TM provided statistical advice. AKW supervised GR during the analyzes and drafting of the paper. All authors critiqued revisions of the paper and approved the final manuscript

\section{Acknowledgements}

We appreciate the expert technical assistance and help with the data collection of our osteoporosis nurses Hanne Vestaby, Ann Haestad and Tove Kjoestvedt. This work has been supported and funded by The Competence Development Fund of Southern Norway and Sørlandet Hospital HF. Gudrun Rohde is a recipient of a research career grant from The Competence Development Fund of Southern Norway, Sorlandet Hospital HF and Health Southern Norway Regional Trut.

\section{References}

I. Cummings SR, Melton LJ: Epidemiology and outcomes of osteoporotic fractures. Lancet 2002, 359:176I-1767.

2. O'neill TW, Cooper C, Finn JD, Lunt M, Purdie D, Reid DM, Rowe R, Woolf AD, Wallace WA: Incidence of distal forearm fracture in British men and women. Osteoporos Int 200I, I 2:555-558.

3. Finsen V, Benum P: Colles' fracture as an indicator of increased risk of hip fracture. An epidemiological study. Ann Chir Gynaecol 1987, 76:114-118.

4. Mallmin H, Ljunghall S, Persson I, Naessen T, Krusemo UB, Bergstrom $\mathrm{R}$ : Fracture of the distal forearm as a forecaster of subsequent hip fracture: a population-based cohort study with 24 years of follow-up. Calcif Tissue Int 1993, 52:269-272.

5. Brenneman SK, Barrett-Connor E, Sajian S, Markson LE, Siris ES: Impact of recent fracture on health-related quality of life in postmenopausal women. J Bone Miner Res 2006, 21:809-816.

6. MacDermid JC, Roth JH, Richards RS: Pain and disability reported in the year following a distal radius fracture: a cohort study. BMC Musculoskelet Disord 2003, 4:24.

7. Hallberg I, Rosenqvist AM, Kartous L, Lofman O, Wahlstrom O, Toss $\mathrm{G}$ : Health-related quality of life after osteoporotic fractures. Osteoporos Int 2004, I 5:834-84I.

8. WHO: ICF: International Classification of Functioning, Disability and health. Geneva 2001 [http://www.who.int/classification/ icf].

9. Burckhardt CS, Anderson KL: The Quality of Life Scale (QOLS): Reliability, Validity, and Utilization. Health Qual Life Outcomes 2003, I:60.

10. Anzarut A, Johnson JA, Rowe BH, Lambert RG, Blitz S, Majumdar SR Radiologic and patient-reported functional outcomes in an elderly cohort with conservatively treated distal radius fractures. J Hand Surg [Am] 2004, 29: I I 2I-II 27.

II. Jaremko JL, Lambert RG, Rowe BH, Johnson JA, Majumdar SR: Do radiographic indices of distal radius fracture reduction predict outcomes in older adults receiving conservative treatment? Clin Radiol 2007, 62:65-72.

12. Wakefield $A E, M c Q u e e n$ MM: The role of physiotherapy and clinical predictors of outcome after fracture of the distal radius. J Bone Joint Surg Br 2000, 82:972-976.

13. Grewal R, MacDermid JC, Pope J, Chesworth BM: Baseline predictors of pain and disability one year following extra-articular distal radius fractures. Hand 2007, 2:104- III.

14. Altman DG: Practical statistics for medical research London; New York: Chapman and Hall; 2006.

15. McLellan AR, Gallacher SJ, Fraser M, McQuillian C: The fracture liaison service: success of a program for the evaluation and management of patients with osteoporotic fracture. Osteoporos Int 2003, I4:1028-1034.

16. Handoll HH, Huntley JS, Madhok R: External fixation versus conservative treatment for distal radial fractures in adults. Cochrane Database Syst Rev 2007, I 8(3):CD006194.

17. Consensus development conference: diagnosis, prophylaxis, and treatment of osteoporosis. Am J Med 1993, 94:646-650.

18. Pincus T, Summey JA, Soraci SA Jr, Wallston KA, Hummon NP: Assessment of patient satisfaction in activities of daily living using a modified Stanford Health Assessment Questionnaire. Arthritis Rheum 1983, 26: I346-I353.

19. Pincus T, Callahan LF, Brooks RH, Fuchs HA, Olsen NJ, Kaye J]: Selfreport questionnaire scores in rheumatoid arthritis compared with traditional physical, radiographic, and laboratory measures. Ann Intern Med 1989, I I 0:259-266.

20. Pincus T, Swearingen C, Wolfe F: Toward a multidimensional Health Assessment Questionnaire (MDHAQ): assessment of advanced activities of daily living and psychological status in the patient-friendly health assessment questionnaire format. Arthritis Rheum 1999, 42:2220-2230.

21. Kvien TK, Kaasa S, Smedstad LM: Performance of the Norwegian SF-36 Health Survey in patients with rheumatoid arthritis. II. A comparison of the SF-36 with disease-specific measures. Clin Epidemiol 1998, 5 I:1077-1086.

22. Haavardsholm EA, Kvien TK, Uhlig T, Smedstad LM, Guillemin F: A comparison of agreement and sensitivity to change between AIMS2 and a short form of AIMS2 (AIMS2-SF) in more than I,000 rheumatoid arthritis patients. I Rheumatol 2000 , 27:2810-2816.

23. Ware JE Jr, Snow KK, Kosinski MA, Gandek MS: SF-36 Health Survey Manual \& Interpretation Guide Boston: Massachusetts: New England Medical Centre, The Health Institute; 1993.

24. Ware JE Jr, Kosinski MA, Keller SD: SF-36 Physical and Mental health Summery Scale: A User's Manual Boston: Massachusetts: New England Medical Centre, The Health Institute; 1994.

25. Loge JH, Kaasa S: Short form 36 (SF-36) health survey: normative data from the general Norwegian population. Scand I Soc Med 1998, 26:250-258.

26. Loge JH, Kaasa S, Hjermstad MJ, Kvien TK: Translation and performance of the Norwegian SF-36 Health Survey in patients with rheumatoid arthritis. I. Data quality, scaling assumptions, reliability, and construct validity. J Clin Epidemiol 1998 51:1069-1076.

27. Burckhardt CS, Woods SL, Schultz AA, Ziebarth DM: Quality of life of adults with chronic illness: a psychometric study. Res Nurs Health 1989, I 2:347-354.

28. Burckhardt CS, Anderson KL, Archenholtz B, Hagg O: The Flanagan Quality of Life Scale: Evidence of Construct Validity. Health Qual Life Outcomes 2003, I:59.

29. Burckhardt CS, Archenholtz B, Bjelle A: Quality of life of women with systemic lupus erythematosus: a comparison with women with rheumatoid arthritis. I Rheumatol 1993, 20:977-98।

30. Liedberg GM, Burckhardt CS, Henriksson CM: Validity and reliability testing of the Quality of Life Scale, Swedish version in women with fibromyalgia - statistical analyses. Scand J Caring Sci 2005, 19:64-70.

31. Grov EK, Dahl AA, Fossa SD, Wahl AK, Moum T: Global quality of life in primary caregivers of patients with cancer in palliative phase staying at home. Support Care Cancer 2006, I 4:943-95 I

32. Wahl A, Burckhardt C, Wiklund I, Hanestad BR: The Norwegian version of the Quality of Life Scale (QOLS-N). A validation and reliability study in patients suffering from psoriasis. Scand I Caring Sci 1998, I 2:2 1 5-222.

33. Fayers PM, Machin D: Quality of life: the assessment, analysis and interpretation of patient-reported outcomes Chichester: John Wiley; 2007.

34. Revicki DA, Osoba D, Fairclough D, Barofsky I, Berzon R, Leidy NK, Rothman M: Recommendations on health-related quality of life research to support labeling and promotional claims in the United States. Qual Life Res 2000, 9:887-900.

35. Kosinski M, Kujawski SC, Martin R, Wanke LA, Buatti MC, Ware JE Jr, Perfetto EM: Health-related quality of life in early rheumatoid arthritis: impact of disease and treatment response. Am J Manag Care 2002, 8:231-240.

36. Spirduso W: Physical dimentions of Aging Human Kinitics, USA; 1995. 
37. Wahl AK, Rustoen T, Hanestad BR, Lerdal A, Moum T: Quality of life in the general Norwegian population, measured by the Quality of Life Scale (QOLS-N). Qual Life Res 2004, I3:1001-1009.

38. Andersen MH, Mathisen L, Veenstra M, Oyen O, Edwin B, Digernes R, Kvarstein G, Tonnessen TO, Wahl AK, Hanestad BR, Fosse E: Quality of life after randomization to laparoscopic versus open living donor nephrectomy: long-term follow-up. Transplantation 2007, 84:64-69.

39. Bo K, Talseth T, Vinsnes A: Randomized controlled trial on the effect of pelvic floor muscle training on quality of life and sexual problems in genuine stress incontinent women. Acta Obstet Gynecol Scand 2000, 79:598-603.

40. Ferrans CE, Zerwic JJ, Wilbur JE, Larson JL: Conceptual model of health-related quality of life. J Nurs Scholarsh 2005, 37:336-342.

4I. Ferrans CE: Differences in what quality-of-life instruments measure. J Natl Cancer Inst Monogr 2007, 37:22-26.

42. Covinsky KE, Wu AW, Landefeld CS, Connors AF Jr, Phillips RS, Tsevat J, Dawson NV, Lynn J, Fortinsky RH: Health status versus quality of life in older patients: does the distinction matter? $\mathrm{Am} J$ Med 1999, 106:435-440.

43. Osoba D: Translating the science of patient-reported outcomes assessment into clinical practice. J Natl Cancer Inst Monogr 2007, 37:5-II.

44. Spilker B: Quality of life and pharmacoeconomics in clinical trials Philadelphia: Lippincott-Raven; 1996.

45. Wilson IB, Cleary PD: Linking clinical variables with healthrelated quality of life. A conceptual model of patient outcomes. JAMA 1995, 273:59-65.

46. Mathisen L, Andersen MH, Veenstra M, Wahl AK, Hanestad BR, Fosse E: Quality of life can both influence and be an outcome of general health perceptions after heart surgery. Health Qual Life Outcomes 2007, 5:27.

47. Kempen GI, Brilman El, Ranchor AV, Ormel J: Morbidity and quality of life and the moderating effects of level of education in the elderly. Soc Sci Med 1999, 49: I43-149.

48. Sprangers MA, Schwartz CE: Integrating response shift into health-related quality of life research: a theoretical model. Soc Sci Med 1999, 48: I507-I5I5.

49. Brown JB, Adams ME: Patients as reliable reporters of medical care process. Recall of ambulatory encounter events. Med Care 1992, 30:400-4II.

50. Schmier JK, Halpern MT: Patient recall and recall bias of health state and health status. Pharmacoeconomics Outcome Res 2004, 2:159-163.

5I. Seymour DG, Ball AE, Russell EM, Primrose WR, Garratt AM, Crawford JR: Problems in using health survey questionnaires in older patients with physical disabilities. The reliability and validity of the SF-36 and the effect of cognitive impairment. J Eval Clin Pract 2001, 7:4I I-4I8.

\section{Pre-publication history}

The pre-publication history for this paper can be accessed here:

http://www.biomedcentral.com/1471-2474/10/106/pre pub

Publish with Bio Med Central and every scientist can read your work free of charge

"BioMed Central will be the most significant development for disseminating the results of biomedical research in our lifetime. "

Sir Paul Nurse, Cancer Research UK

Your research papers will be:

- available free of charge to the entire biomedical community

- peer reviewed and published immediately upon acceptance

- cited in PubMed and archived on PubMed Central

- yours - you keep the copyright 